\title{
Empirical analysis on the illicit trade of cigarettes in Vietnam
}

\author{
Hien Thi Thu Nguyen, ${ }^{1}$ Long Thanh Giang $\odot{ }^{1},{ }^{2,3}$ Toan Ngoc Pham ${ }^{4}$
}

1 Department of Economics, Thuongmai University, Hanoi, Viet Nam

${ }^{2}$ Faculty of Economics, National Economics University, Hanoi, Viet Nam

${ }^{3}$ TIMAS, Thang Long University, Hanoi, Viet Nam

${ }^{4}$ Center for Information, Strategic Analysis and Forecast, Institute of Labour Science and Social Affairs, Hanoi, Viet Nam

\section{Correspondence to}

Dr Hien Thi Thu Nguyen, Department of Economics, Thuongmai University, Hanoi Viet Nam;

chthuhien@tmu.edu.vn

Received 27 December 2019 Revised 26 February 2020 Accepted 4 March 2020 Published Online First 7 May 2020

\section{ABSTRACT \\ Background This paper examined how a higher tax on tobacco would affect illicit trade in Vietnam. Methodology and data This paper used the gap method to estimate the gap between cigarette domestically tax-paid sales and domestic consumption. Data were from the tax-paid sales by the Vietnam Steering Committee on Smoking and Health (VINACOSH), the Vietnam Tobacco Association, the General Tax Department, as well as two rounds of the Global Adult Tobacco Survey in 2010 and 2015.}

Key results The results indicated that Vietnam had a negative volume of illicit trade, either a result of underreporting of tobacco use or due to net smuggling of tax-paid cigarettes out of the country. Furthermore, the trend showed an increased negative volume over time, which indicated that increases in tobacco taxes in the interleading years did not result in an increase in illicit trade in tobaccos in Vietnam.

Conclusions Vietnam's low prices on domestic cigarettes created favourable conditions for cigarette smugglers and provided easy access to illicit cigarettes for the Vietnamese people, but the absence of a relationship between tax changes and smuggling suggested that potential increases in the excise tax should not be discouraged by the threat of an increase in illicit trade. The government should increase taxes on cigarettes to raise domestic cigarette prices and take strong policy measures to create a more transparent social environment, therefore effectively reducing the prevalence of illicit cigarettes in Vietnam.

\section{BACKGROUND}

Tobacco use is the most preventable cause of disease and death worldwide. Tobacco use leads to approximately seven million deaths each year ${ }^{1}$ and is expected to cause over eight million deaths in $2030 .^{2}$ Vietnam is ranked among the world's top 15 consumers of tobacco, with more than 15 million smokers, and the Vietnamese people spent about VND 22 trillion (or US\$985 million) a year on tobacco, which accounted for about $10 \%$ of total household expenditures. ${ }^{3}$ Data from the Vietnam Tobacco Control Fund showed that the Vietnamese people consumed about 101 billion cigarettes in 2016. It was projected that smoking would lead to more than 50000 deaths annually by $2023 .^{4}$

Given that smoking is extremely harmful to public health, the government of Vietnam has made commitments and implemented measures to control tobacco production and consumption since 2000 . The Government Resolution No. 12/2000/NQ-CP on 'National Tobacco Control Policy 2000-2010' has been implemented by a committee led by the
Ministry of Health $(\mathrm{MOH})$ and draws from most ministries and community organisations. In 2003, Vietnam signed the Framework Convention on Tobacco Control (FCTC) and ratified it in 2004.

Vietnam has an excise tax, namely, the Special Consumption Tax (SCT), on cigarettes for many years. ${ }^{4}$ In 2006, Vietnam reformed the SCT from a tiered rate of $45 \%$ and $65 \%$ on the wholesale price of different types of cigarettes to a uniform rate of $55 \%$ on all cigarettes. In April 2009, the SCT for tobacco increased to $65 \%$ of the wholesale price and increased again to $70 \%$ on 1 January 2016 and to $75 \%$ on 1 January 2019. The base on which the ad valorem tax applies-the wholesale price-is small, meaning that the tax share of price is low. It was reported that excise taxes accounted for $28.7 \%$ of the price of the most sold brand in Vietnam, far below the WHO recommendation of $70 \% .{ }^{1}$ Furthermore, due to undershifting of the tax increase into the price, the increases in the SCT have resulted in very little change in overall price in real terms. ${ }^{5}$ According to the two Global Adult Tobacco Survey (GATS) conducted in 2010 and 2015, the average price of a 20 -cigarette pack declined by $6.3 \%$ in real terms between 2010 and 2015 .

It has been argued that taxes on cigarettes have not been raised high enough to control tobacco consumption. It was also argued that the current tax structure has not been effective in reducing affordability for smokers because the tax did not adjust for inflation and economic growth. ${ }^{5}$ Due to these factors, cigarettes have become more affordable in Vietnam in recent years. Increasing cigarette taxes, along with reforming the tax structure, will ensure decreased affordability and incentivise a reduction in early initiation to smoking, as well as increase smoking cessation.

At the same time, tax increases have also faced strong objections from domestic cigarette manufacturers. The Vietnamese tobacco industry argued that cigarette smuggling activities in Vietnam have been complex and continue to intensify. They attributed this intensification to the higher prices of domestic products caused by the increase of excise tax levied on cigarettes. ${ }^{6}$ With such opposing arguments, the remaining question has been 'How have higher cigarette taxes affected illicit cigarette trade in Vietnam?'.

This paper updated previous estimates of the illicit cigarette trade in Vietnam and assessed changes over time using a gap analysis method. The method estimated the gap between reported consumption from surveys and sales volumes. The WHO FCTC Protocol to Eliminate Illicit Trade in Tobacco Products ${ }^{7}$ defined illicit trade as 'any practice or conduct prohibited by law and which relates 
to production, shipment, receipt, possession, distribution, sale or purchase, including any practice or conduct intended to facilitate such activity'. This was a broad definition of illicit trade; however, for the purposes of this paper, illicit trade was considered as trade without partial or full payment of taxes. This might take the form of tax evasion, which is an illegal means of circumventing the partial or full payment of taxes like smuggling, or tax avoidance, which is a legal mechanism to avoid paying taxes.

The aim of this paper was also to provide policymakers with an updated evidence on the magnitude and trend of the illicit cigarette trade in Vietnam. This paper was hoped to be a reference for policymakers in drafting cigarette tax policies, as well as for tax administrators and enforcement agencies in effectively curbing the tobacco epidemic and in finding solutions to illicit cigarette trade in Vietnam.

\section{Literature review}

Measuring levels and trends in illicit trade can be challenging. A body of literature on the subject has been developed applying different methods, each with their strengths and weaknesses. A number of the studies on the effect of higher taxes on illicit trade imply two alternative outcomes: higher taxes on tobacco result in illicit trade, or higher taxes do not result in illicit trade. The reality is less clear cut. For instance, on the global scale, it was estimated that governments lost US $\$ 40.5$ billion a year due to illicit trade. ${ }^{8}$ Evidence from Canada, France, Sweden and the UK, however, suggested that higher taxes could still lead to increases in revenues even in the presence of illicit trade. ${ }^{89}$

In fact, illicit trade in tobacco is not only influenced by tobacco taxes, but is also affected by other factors which need to be considered in any analysis. For example, Health Canada ${ }^{10}$ showed various reasons for increased illicit trade of tobacco other than tax increases, including a misconception by the general public that the purchase of cigarettes on First Nations reserves was legal (these were reserves set aside for indigenous populations that have special tax laws), a lack of publicity/information on the illicit nature of these cigarettes, easy access to tobacco, lack of police presence and enforcement and open advertising of discount cigarettes on highways. As cited by Schwartz and Zhang, ${ }^{11}$ increasing cigarette taxes and improving anti-illicit enforcement resulted in decreased illicit trade, decreased cigarette consumption and increased tax revenues. It was found that cigarette smuggling was not caused by a difference in tax levels in Central and Eastern Africa where cigarette prices were only US $\$ 0.60$ per pack. ${ }^{12}$ It was generally indicated that corruption, tolerance of illicit trade and weak state capacity were more important than price or tax increases, implying that tax alone could not solve the problem of illicit trade of tobacco. ${ }^{11}$

One recently used method for estimating cigarette tax evasion and avoidance has been the 'gap analysis', which compares the difference between tax-paid cigarette sales and the measured population consumption. This method has been applied in a number of countries. Blecher ${ }^{13}$ estimated the size of the market for illicit cigarettes in South Africa during 1997-2007. The market size for illicit cigarettes was calculated using data on smoking prevalence and simulated smoking intensity. The results showed that the size of the illicit market grew substantially to between $9.4 \%$ and $11.5 \%$ of the total market during the studied period, and that those numbers were significantly lower than the anecdotal claims of the tobacco industry. While scale of the illicit market was significant, it did not undermine tobacco control policy as consumption size in both the illicit and legal markets declined consistently, and tax revenue from higher excise taxes compensated for the taxes lost from illicit trade.

Using a gap analysis method, Paraje ${ }^{14}$ estimated cigarette tax evasion and avoidance for Argentina, Brazil, Chile, Colombia and Peru and used nationally representative surveys to measure population consumption. The author found that illicit cigarette trade as a percentage of total sales increased in Brazil in recent years, while illicit trade in Argentina remained stable after a relative decrease during 2005-2009. Chile, Colombia and Peru showed no clear evidence of any increase in illicit cigarette trade, despite substantial price increases in Chile as well as tax increases in both Colombia and Peru.

Three methodologies have been used to estimate illicit trade in Vietnam. Nguyen et $a l^{15}$ employed the gap method as well as trade discrepancies, while Nguyen $e t a l^{16}$ used a survey of smokers and inspection of cigarette packs.

Using data from the Vietnam Living Standards Survey 1998, the Vietnam Household Living Standards Survey 2006, the Vietnam National Health Survey 2002 and the GATS 2010, Nguyen $e a^{15}$ measured the magnitude of illicit cigarette trade for Vietnam between 1998 and 2010 using a gap analysis and trade discrepancies as recorded by Vietnam and trade partners. The research indicated that Vietnam experienced net smuggling, and discrepancies in trade records indicated that the value of smuggled cigarettes into Vietnam ranged from US $\$ 100$ million to $\$ 300$ million during $2000-2010$, and that these cigarettes were primarily originated from Singapore, Hong Kong, Macao, Malaysia and Australia.

Using data from GATS in 2010 and the Tobacco Consumption Survey in 12 provinces in 2012, Nguyen et al ${ }^{16}$ found there was substantial illicit cigarette consumption in Vietnam: 20.68\% of all smoked cigarettes were illegal, which was much higher than the average shares of illegal cigarettes at 9.8\%, $11.8 \%$ and $16.8 \%$ in high-income, middle-income and low-income countries, respectively. The authors also found that the average price of legal cigarettes in Vietnam was US $\$ 0.55$, which was less than half the average price of legal cigarettes in low-income countries and one-tenth of that in high-income countries. The paper concluded that the combination of high illicit market share and lower-priced cigarettes in Vietnam as compared with other countries suggested that high tax and price were not the most important factors determining the scale of cigarette smuggling. The most striking finding of this research was that the prices of illegal cigarettes in Vietnam were consistently and significantly higher than prices of legal products. The authors provided a possible explanation for this: illicit smokers in Vietnam were not motivated by economic factors; rather, they might perceive illicit cigarettes to have superior quality compared with those made locally.

Although the gap analysis has proven its validity in estimating illicit tobacco trade in many countries at different income levels and under different legislations for tobacco control, it still has some key limitations. As addressed by Paraje,${ }^{14}$ the consumption gap analysis could not provide an estimate of the size of the market for illicit products but instead showed a trend in its evolution. Consequently, the number of illicit cigarettes or lost tax revenue was not calculated. More importantly, this method prevented the report from distinguishing between the different components of non-registered consumption or product counterfeiting. Thus, with under-reporting, it must be assumed that the proportional share of each of these components remained stable over time (ie, deviations in the trend implied deviations in illicit trade). Also, when conducting surveys on cigarette consumption, it should be assumed that the proportion of illicit cigarette 
consumption for the non-surveyed groups (such as those aged 65 and over) was similar to that of the registered cigarettes among the rest of the population.

\section{METHODS AND DATA SOURCES Methods}

To estimate the magnitude of the illicit cigarette trade, a gap method was employed to update, ${ }^{15}$ that is, comparing cigarette sales against consumption.

The method estimates the consumption of illicit cigarettes by calculating the discrepancy between domestic tax-paid sales of cigarettes and a survey-based estimate of consumption.

The report has the equilibrium of cigarette flows in and out of Vietnam in one calendar year, as follows:

Cigarettes domestically manufactured+cigarettes smuggled into Vietnam+cigarettes legally imported into Vietnam+cigarettes in stock at the end of the previous year=domestic cigarettes consumed+cigarettes legally exported from Vietnam + cigarettes smuggled out of Vietnam+cigarettes in stock at the end of the year of interest

Assuming that the stock of cigarettes at the end of all years is equal:

Cigarettes domestically manufactured + cigarettes smuggled into Vietnam + cigarettes legally imported into Vietnam $=$ domestic cigarettes consumed + cigarettes legally exported from Vietnam+ cigarettes smuggled out of Vietnam.

Thus,

(Cigarettes domestic consumed-cigarettes domestically manufactured $)+($ cigarettes legally exported by Vietnam-cigarettes legally imported into Vietnam $)=($ cigarettes smuggled into Vietnam-cigarettes smuggled out of Vietnam).

In one calendar year,

$$
D=S M U G I N-S M U G O U T,
$$

in which

- $D=$ (cigarettes domestically consumed-cigarettes domestically manufactured) + (cigarettes legally exported by Vietnam-cigarettes legally imported).

- SMUGIN= cigarettes smuggled into Vietnam.

- SMUGOUT=cigarettes smuggled out of Vietnam. If $D>0$, SMUGIN-SMUGOUT $>0=>$ SMUGIN $>$ SMUGOUT; thus, Vietnam experienced a net illicit cigarette inflow.

If $D<0$, SMUGIN-SMUGOUT <0 = > SMUGIN <SMUGOUT; thus, Vietnam experienced a net illicit cigarette outflow.

Thus, the estimated discrepancy $(D)$ would be the net illicit cigarettes into Vietnam.

\section{Data sources}

Data on the quantity of domestically produced and then domestically sold cigarettes (equivalent to domestic cigarettes manufactured minus export), as well as cigarettes legally imported were obtained from the Vietnam Tobacco Union, Vietnam Steering Committee on Smoking and Health (VINACOSH) and the General Custom Office of Vietnam.

Domestic cigarettes consumed figures were estimated as follow:

Domestic cigarettes consumed in a year=average number of smoked cigarettes per day $\times 365$ days $\times$ vumber of smokers,

in which
Number of smokers= cigarette smoking prevalence by gender/ age group $\times$ population by corresponding categories.

Cigarette smoking prevalence and average number of smoked cigarette per day by gender and age group (15-24, 25-34, 35-44, 45-54, 55-64 and 65+) in 2010 and 2015 were calculated from GATS 2010 and GATS 2015.

GATS was a nationally representative household survey of adults from 15 years of age using a standard core questionnaire, sample design, as well as data collection and management procedures that are reviewed and approved by international experts. GATS was first implemented in Vietnam in 2010 and then repeated in 2015. The surveys were conducted by $\mathrm{MOH}$ in cooperation with Hanoi Medical University and the General Statistics Office of Vietnam (GSO). Both surveys used a twotiered stratified random sampling technique to generate nationally representative datasets. A total of 9925 individual interviews were conducted in the 2010 census, reaching a response rate of $92.8 \%$. In 2015, there were 8996 individual interviews conducted, reaching a response rate of $95.8 \%$. In both 2010 and 2015 GATS, the question used to estimate smoking prevalence was 'Do you currently smoke tobacco on a daily basis, less than daily or not at all?' Smokers were those who responded 'daily' or 'less than daily'. Regular smokers were those who said daily, and occasional smokers were those who replied less than daily. The question 'On average, how many of the following products do you currently smoke each day?' was used to identify the average number of sticks smoked daily. Based on these questions and each respondent's gender and age, the smoking prevalence of regular and occasional smokers by gender and age in 2010 and 2015 could be estimated. Only smoking prevalence for people aged 15 years and older was obtained from these surveys.

Population, by age group and gender, was calculated from the Statistical Yearbook by the GSO.

As GATS 2010 and 2015 only allowed to have national data for 2 years, we needed to calculate smoking rates by age group for 2011, 2012, 2013, 2014 and 2016 using the small area estimation (SAE) method combining GATS, as well as the Labour Force Survey (LFS). The SAE method is more widely used in poverty rate estimations but can also be applied for estimating smoking rates for men and women at provincial and national levels. This method was applied in Berkowitz et $a l^{17}$ and Song et al. ${ }^{18}$

Generalising the data from GATS, various factors were estimated (such as sex, age, educational level, working status, working sector, household income and expenditure), which possibly affected smoking probability, or the average number of smoked cigarettes of person $i$ at location $j$ using a logistic model as follows:

$$
\mathrm{L}_{\mathrm{i}}=\operatorname{In}\left(\frac{\mathrm{P}_{\mathrm{i}}}{1-\mathrm{P}_{\mathrm{i}}}\right)=\mathrm{Z}_{\mathrm{i}}=\beta_{0}+\beta_{1} \times_{1}+\beta_{2} \times{ }_{2}+\ldots+\beta_{\mathrm{k}} \times_{\mathrm{k}},(7)
$$

in which $P_{i}$ was the probability for person $i$ to be a smoker; $X_{1}, X_{2}, \ldots, X_{k}$ were independent variables representing person $i$ 's characteristics.

With the data from GATS, coefficients for $X_{i}$ were estimated. For each observation, the value of $P_{i}$ was calculated as follows:

$$
P_{i}=\frac{1}{1+e^{-Z i}}=\frac{1}{1+e^{-}\left(\beta_{0}+\beta_{1} \times{ }_{1}+\beta_{2} \times{ }_{2}+\ldots+\beta_{k} \times k\right)}
$$

As mentioned, data on smoking rates in 2011, 2012, 2013, 2014 and 2016 were not available. As such, in order to estimate a smoking rate for these years, we used the estimated coefficients of the aforementioned logistic model, along with respective characteristics collected from the LFS (a national sample for provinces and the country). Using this dataset helped estimate 


\begin{tabular}{|c|c|}
\hline Indicators to be estimated/data & Sources \\
\hline Average sticks smoked per day & Ministry of Health (GATS 2010, 2015) \\
\hline Smoking prevalence 2010, 2015 & Ministry of Health (GATS 2010, 2015) \\
\hline Cigarette domestic sale (tax-paid sale) & Vietnam Tobacco Union, VINACOSH, Vinataba \\
\hline Cigarette import & $\begin{array}{l}\text { Vietnam Tobacco Association and General } \\
\text { Department of Custom }\end{array}$ \\
\hline Population characteristics & General Statistics Office \\
\hline
\end{tabular}

$P_{i}$ for each observation from the LFS, which in turn helped estimate smoking rates at provincial and national levels.

The average number of sticks smoked per day calculated from GATS 2010 was applied to years 2011, 2012 and 2013. The numbers calculated from GATS 2015 were applied to years 2014 and 2016, assuming that smoking intensity stayed constant during the years.

Due to the well-known understatement of the quantity of tobacco consumed by respondents, adjustments should be made to ensure that the estimated tobacco consumption was accurate. Based on the previous study implemented by Nguyen et al,,${ }^{15}$ the under-reporting rates of $10 \%, 20 \%$ and $30 \%$ were applied to the sensitivity analysis.

Table 1 presents sources of data used for calculations.

\section{ESTIMATION RESULTS}

The gap method, which compared cigarette consumption and tax-paid domestic sales in each year from 2010 to 2016, showed interesting and unexpected results. The discrepancies between these two figures were negative. This result implied that Vietnam was a net supplier rather than a net recipient of illicit cigarettes. This could also mean that cigarettes were smuggled out of Vietnam. Table 2 presents the results with several different under-reporting assumptions.

Without under-reporting, the total cigarette consumption increased from 2712 million packs in 2010 to 2927 million packs in 2011 and remained nearly unchanged from 2011 to 2016. Cigarette domestic tax-paid sales generally rose throughout the period, from 3986 million packs in 2010 to 5067 million packs in 2016. The estimated results of tobacco consumption in 2010 were slightly higher than those estimated from the previous study

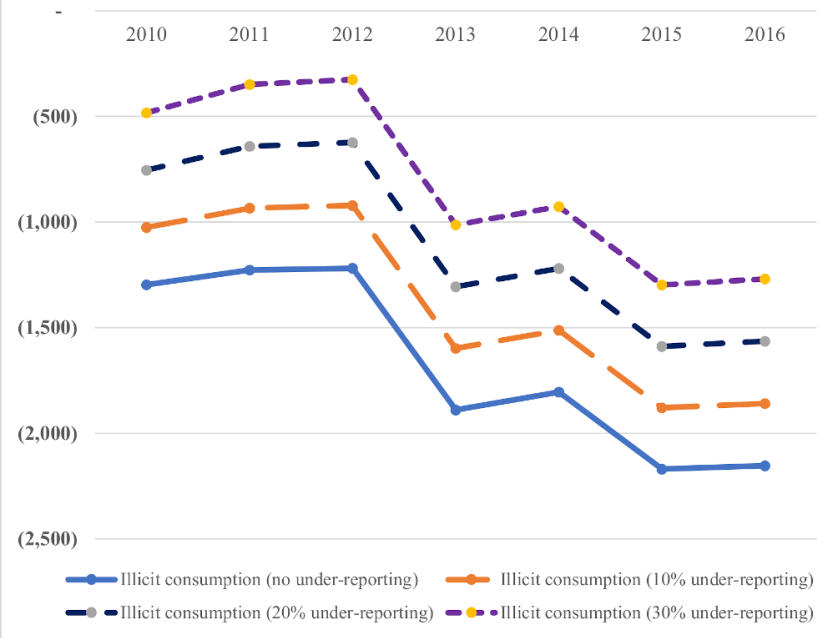

Figure 1 Trend in the gap analysis with all three under-reporting scenarios showing the increasing negative gap over time.

by Nguyen et al..${ }^{15}$ The difference could be attributed to this estimate by the total cigarette consumption of regular and irregular smokers (while Nguyen et $a l^{15}$ estimated cigarette consumption by regular smokers only).

The negative values for discrepancies between total cigarette consumption and tax-paid domestic sale indicate that the number of cigarettes smuggled into Vietnam was smaller than the number smuggled out of Vietnam; in other words, Vietnam experienced a net outflow of illicit cigarettes from 2010 to 2016. The magnitude of illicit cigarette net outflow fluctuated with an increasing trend. If the respondent's under-reporting was assumed to be $30 \%$, the magnitude of illicit cigarette ranged from 326 million packs to 1298 million packs, which was respectively from $10.9 \%$ to $44.6 \%$ of total consumption from 2010 through 2016 (figure 1 and table 2).

\section{DISCUSSION}

The results of this paper indicated that Vietnam had a negative volume of illicit trade. This also meant that there was a net illicit outflow from Vietnam, for example, due to net smuggling out of the country resulting from tax-paid products produced in Vietnam being smuggled to other countries. This interpretation

\begin{tabular}{|c|c|c|c|c|c|c|c|}
\hline Measure & 2010 & 2011 & 2012 & 2013 & 2014 & 2015 & 2016 \\
\hline Estimated consumption & 2712 & 2927 & 2977 & 2919 & 2926 & 2907 & 2948 \\
\hline Import $^{2}$ & 22.3 & 22.3 & 22.3 & 22.3 & 22.3 & 32.1 & 34.7 \\
\hline Illicit consumption (no under-reporting) & $(1297)$ & $(1227)$ & (1219) & $(1889)$ & $(1805)$ & $(2170)$ & $(2154)$ \\
\hline Illicit consumption ( $10 \%$ under-reporting) & $(1026)$ & (934) & (921) & (1598) & $(1512)$ & (1879) & (1859) \\
\hline Illicit consumption ( $30 \%$ under-reporting) & (483) & (349) & (326) & (1014) & (927) & (1298) & $(1270)$ \\
\hline Illicit consumption as share of total consumption (10\%) & $-37.8 \%$ & $-31.9 \%$ & $-30.9 \%$ & $-54.7 \%$ & $-51.7 \%$ & $-64.6 \%$ & $-63.1 \%$ \\
\hline Illicit consumption as share of total consumption ( $20 \%)$ & $-27.8 \%$ & $-21.9 \%$ & $-20.9 \%$ & $-44.7 \%$ & $-41.7 \%$ & $-54.6 \%$ & $-53.1 \%$ \\
\hline Illicit consumption as share of total consumption (30\%) & $-17.8 \%$ & $-11.9 \%$ & $-10.9 \%$ & $-34.7 \%$ & $-31.7 \%$ & $-44.6 \%$ & $-43.1 \%$ \\
\hline
\end{tabular}

${ }^{1}$ Data from 2010-11

${ }^{2}$ Data from 2013-16

Note: Numbers in parentheses are negative

Source: Data for 2010, 2011 and 2012 were extracted from a public report by Vinataba, 'Domestic consumption of cigarette' (https://tuoitre.vn/2012-viet-nam-tieu-thu-4174-tibao-thuoc-la-575893.htm); data for 2013-2016 were extracted from the report of Tobacco Control Fund (Vinacosh). 
would mean that in 2010, between 483 million and 1297 million packs might be legally produced, taxed and then transported to other countries. These figures ranged from 1270 million in 2010 to 2154 million in 2016. Since exported cigarettes were not subject to taxes, we might assume that the Vietnamese cigarette exporters had no incentives to under-report their exports. However, cigarette exporters still had incentives to export illegally. One of the possible underlying reasons was that domestic tobacco companies tried to avoid high import and specific consumption taxes in other countries. Domestic companies could not report lower outputs due to strong supervision by authorities. Also, although they must pay specific consumption tax, domestically produced tobaccos still had lower prices than those imported, and thus the companies fully reported their outputs. An alternative hypothesis was that the surveys suffered from under-reporting of tobacco use, either smoking prevalence or smoking intensity, or both. This was, however, considered by adjusting tobacco consumption accordingly to under-reporting rate at $10 \%, 20 \%$ and $30 \%$.

Although the gap analysis method was criticised that it was a poor method in estimating illicit trade magnitude for a particular year because surveys were usually face under-reporting issue, it has been still the best one to analyse the trend of illicit trade over time. The results of this paper showed that negative magnitude of illicit trade increased significantly over time; in other words, illicit trade declined over time.

In 2016, excise tax rates levied on domestically manufactured cigarettes were increased from $65 \%$ to $70 \%$ of the wholesale prices. Based on the tobacco industry narratives, the number of cigarettes smuggled into Vietnam was expected to rise due to this increase. However, our estimation indicated that Vietnam still experienced a net smuggling out in 2016, and such a net smuggling out had increased since 2010. There was no evidence to establish a relationship between a tax increase and illicit cigarette consumption. Furthermore, by showing an increasing trend in the negative gap over time, the results clearly showed that increases in excise taxes did not result in increases in tax avoidance and evasion over time.

The apparent decline in illicit trade that coincided with the tax increase might reflect better enforcement, or that increased domestic prices might reduce the price differential between domestic and illicitly imported cigarettes. In fact, the illicit cigarettes in Vietnam were usually more expensive than the tax-paid cigarettes. ${ }^{15}$ Thus, increasing domestic prices would reduce such a price differential and shift consummation from illicitly imported to domestically tax-paid cigarettes.

\section{CONCLUSIONS}

Vietnam's low prices on domestic cigarettes have created favourable conditions for cigarette smugglers and have provided easy access to illicit cigarettes for the Vietnamese people. The absence of a relationship between tax changes and smuggling, however, suggested that potential increases in the excise tax should not be discouraged by the threat of an increase in illicit trade. The government should increase taxes on cigarettes to raise domestic cigarette prices and take strong policy measures to create a more transparent social environment, therefore effectively reducing the prevalence of illicit cigarettes in Vietnam.

Although this paper could provide some evidence to confirm the same findings as those from the previous studies, the comparison has some limitations due to the available data. First, as we must apply the SAE method for estimating smoking rates for various population groups in terms of age and sex, some other important factors influencing smoking situations might be missed. For instance, we did not know whether grandparents, parents or other close relatives of the observed people were also smokers, or what the sources were for tax-paid cigarettes. Moreover, the SAE method depended heavily on weighted estimates as this method needs to consider proportions of certain groups of people. Second, the estimates measured the magnitude of illicit cigarettes present in the market but could not distinguish whether these cigarettes were originated domestically or abroad. Last but not least, we could not take into account a number of other factors which might also strongly affect illicit trade. For example, along with increased tax, law enforcement as well as public education might be good policy actions to decrease tobacco use, curb contraband tobacco and increase tobacco tax revenue.

What this paper adds

- We provided an up-to-date study with different methods in estimating the cigarette illicit market in Vietnam, along with tax increases.

- We added another evidence-based study to demonstrate that tax increases would not result in the illicit cigarette trade.

Acknowledgements We are grateful to Evan $\mathrm{H}$ Blecher and his technical team at University of Illinois at Chicago (UIC) for their insightful comments on various drafts of this paper, Sharon Feldman and her administrative team at UIC for their timely support, and Professor Dat Tho Tran and Ms Yen Hai Thi Nguyen at National Economics University for their encouragements and support. All possible errors, however, are ours.

Contributors HTTN developed the idea for this research, provided the data analysis and prepared the first draft of the paper. LTG prepared the literature review, checked the data calculation and consistency, and revised and edited the full manuscript. TNP assisted with the data analysis on cigarette use.

Funding This paper was funded by the University of Illinois at Chicago's Institute for Health Research and Policy through its partnership with Bloomberg Philanthropies

Competing interests This paper was submitted as part of the Illicit Trade Supplement by Cancer Research UK and University of Illinois at Chicago.

Patient consent for publication Not required.

Provenance and peer review Not commissioned; externally peer reviewed.

Data availability statement Data are available upon reasonable request.

\section{ORCID iD}

Long Thanh Giang http://orcid.org/0000-0002-6296-0563

\section{REFERENCES}

1 WHO. Who report on the global tobacco epidemic 2017, 2017

2 Mathers $C D$, Loncar D. Projections of global mortality and burden of disease from 2002 to 2030. PLoS Med 2016;3:e442.

3 Medvedeva N. VINATABA vs. illicit trade. Tobacco Asia, 2016. Available: https://www. tobaccoasia.com/features/vinataba-vs-illicit-trade/ [Accessed Access 23 March 2018].

4 Levy DT, Bales S, Lam NT, et al. The role of public policies in reducing tobacco: policy simulation model. Soc Sci Med 2006;62:1819-30.

5 Blecher E, Thu LT. Vietnam country factsheet: tobacco tax structures. Tobacconomics, 2018. Available: https://tobacconomics.org/wp-content/uploads/2018/08/VietnamPaper-Policy-Brief-FINAL.pdf [Accessed 23 March 2018].

6 Vinataba Newsletter. The fight against cigarette smuggling: reveal many difficulties, 2019. Available: http://www.vinataba.com.vn/App_File/userfiles/files/Thu\%E1\% BB\%91c\%201\%C3\%A1\%20s\%E1\%BB\%91\%201\%20-\%202019.pdf [Accessed 30 November 2019].

7 World Health Organization (WHO). Protocol to eliminate illicit trade in tobacco products, 2013

8 Joossens L, Merriman D, Ross H, et al. The impact of eliminating the global illicit cigarette trade on health and revenue. Addiction 2010;105:1640-9.

9 International Agency for Research on Cancer (IARC). IARC Handbooks of Cancer Prevention, Tobacco Control, Vol. 14: Effectiveness of Tax and Price Policies for Tobacco Control 2015. 
10 Health Canada. Royal Canada mounted police (RCMP) 2008 contraband tobacco enforcement strategy, 2007. Available: http://www.casacubana.ca/documents/pdf/ nouvelles/loi-C-32/PDF4_EN.pdf [Accessed 23 March 2019].

11 Schwartz R, Zhang B. Does increasing tobacco Tax increase contraband? debunking the taxation-contraband tobacco myth, 2015. Available: https://www.otru.org/ wp-content/uploads/2019/02/2015\%20MAY\%2012\%20Does\%20Increasing\% 20Tobacco\%20Tax\%20increase\%20Contraband.pdf [Accessed 23 March 2018].

12 Titeca K, Joossens L, Raw M. Blood cigarettes: cigarette smuggling and war economies in central and eastern Africa. Tob Control 2011;20:226-32.

13 Blecher E. A mountain or a molehill: is the illicit trade in cigarettes undermining tobacco control policy in South Africa? Trends Organ Crime 2010;13:299-315.

14 Paraje G. Illicit cigarette trade in five South American countries: a gap analysis for Argentina, Brazil, Chile, Colombia, and Peru. Nicotine Tob Res 2019;21:1079-86.
15 Nguyen MT, Denniston R, Nguyen HTT, et al. The empirical analysis of cigarette Tax avoidance and illicit trade in Vietnam, 1998-2010. PLoS One 2014;9:e87272.

16 Nguyen MT, Dao ST, Nguyen NQ, et al. Illicit cigarette consumption and government revenue loss in Vietnam: evidence from a primary data approach. Int J Environ Res Public Health 2019;16:pii: E1960.

17 Berkowitz Z, Zhang X, Richards TB, et al. Multilevel small-area estimation of multiple cigarette smoking status categories using the 2012 behavioral risk factor surveillance system. Cancer Epidemiol Biomarkers Prev 2016;25:1402-10.

18 Song L, Mercer L, Wakefield J, et al. Using Small-Area estimation to calculate the prevalence of smoking by Subcounty geographic areas in King County, Washington, behavioral risk factor surveillance system, 2009-2013. Prev Chronic Dis 2016;13:E59. 